\title{
The Social Media and Civic Engagement Matrix
}

Anders Finholt

Kalamazoo College

Kalamazoo, MI 49006, USA

anders.finholt16@kzoo.edu
A.J. Million

University of Michigan, School of Information

Ann Arbor, Ml 48109, USA

millioaj@umich.edu
Libby Hemphill

University of Michigan, School of Information

Ann Arbor, MI 48109, USA

libbyh@umich.edu
KALAMAZOO

COLLEGE

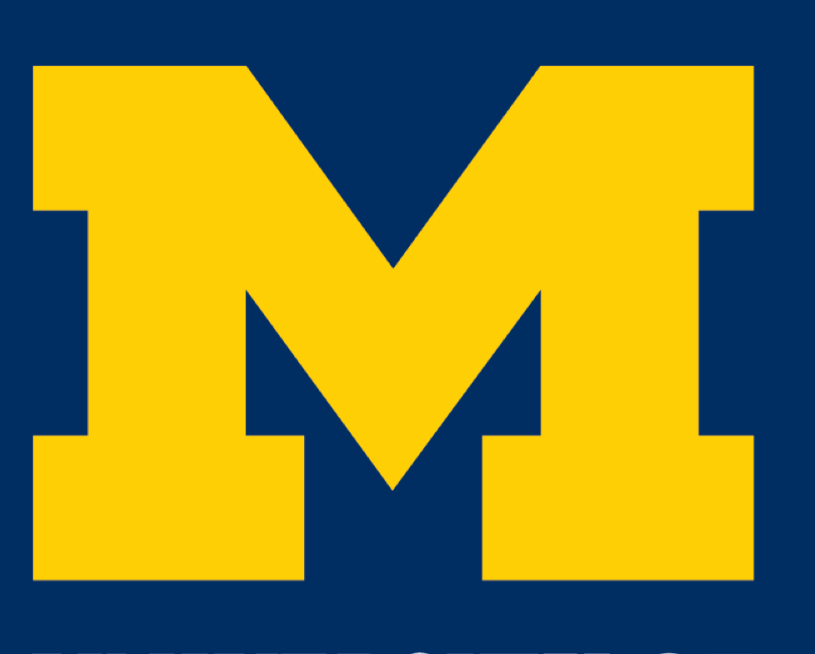

UNIVERSITY OF MICHIGAN

\section{Introduction}

- Studies of online civic engagement often focus on how it improves quality-of-life in democratic countries

- Online engagement activities may benefit communities while violating democratic norms

- We present a matrix for classifying engagement activities along two dimensions: sociality and effect

\section{What We Did}

- We conducted interviews of nonprofit affiliates

- Some participants said civic engagement can be a negative experience

- We developed a way to classify the full range of engagement examples from our interviews while taking norm-violating behaviors into account

\section{The Matrix}

- Classifies perceptions of civic acts and engagement behaviors

- Civic acts either improve or exacerbate quality-of -life

- Antisocial behavior violates or disregards democratic norms

- Prosocial behaviors are positive and align with democratic norms

"There's this greater system that's oppressing people, which has left a lot of people not wanting to be civically engaged or having those conversations."

Kalamazoo Interview Participant 16

"I think most of the time [civic engagement] has a positive intent, but it can go wrong."

- Kalamazoo Interview Participant 13
Social Media and Civic Engagement Matrix

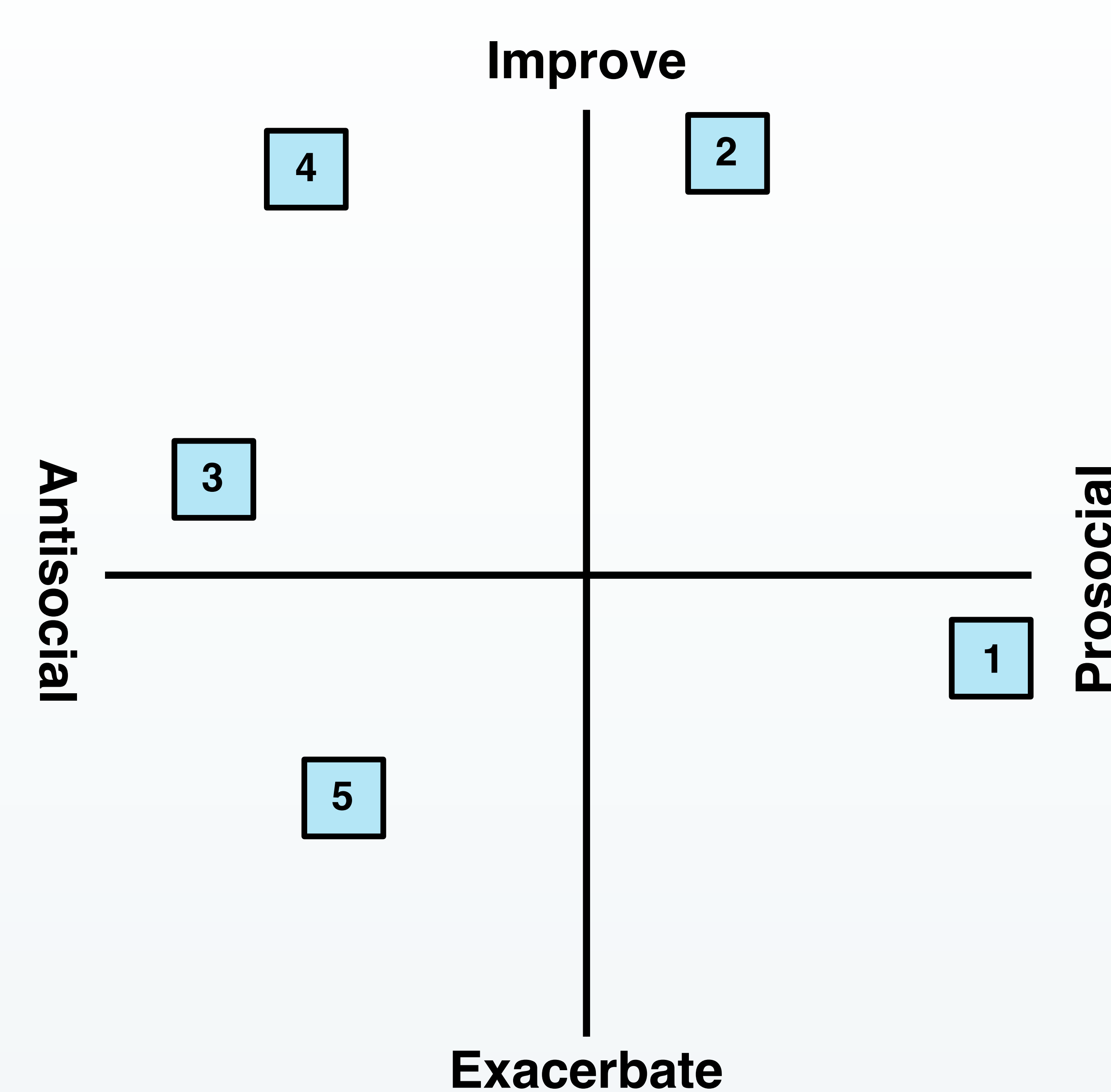

Exacerbate
- Prosocial-effective actions include registering voters and raising money for a charitable cause

- Antisocial-improve actions are disruptive but effective due to the conflict they create or reveal

- Prosocial-exacerbate actions follow social norms but have little impact

- Antisocial-exacerbate actions violate norms and make life worse

"Civic engagement would be... working as a community to fight for something."

$$
\text { - Chicago Interview Participant } 14
$$

"I see people share a lot of articles, but then that's all they do."

- Chicago Interview Participant 12
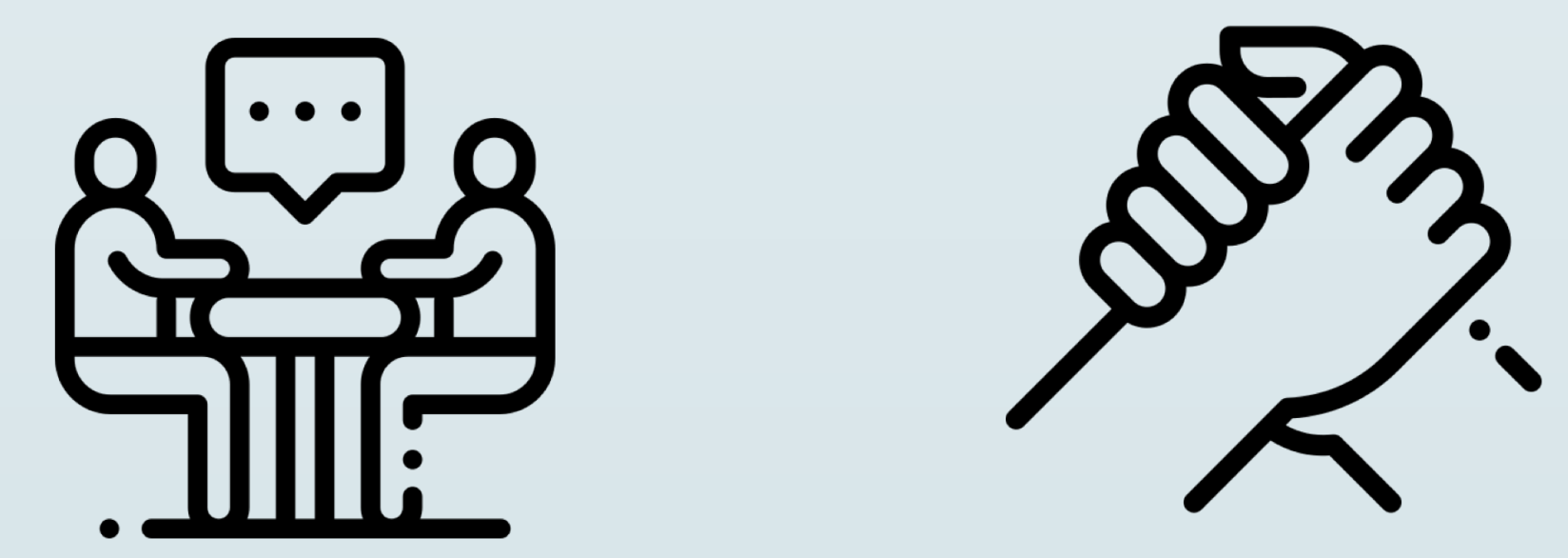

\section{Engagement Examples}

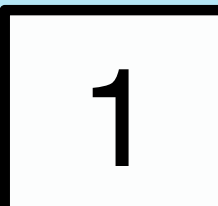

Changing a Facebook profile picture as a show of solidarity for the survivors of a natural disaster rather than donating to relief efforts.

2 Registering citizens to vote via social media.

Posting stolen emails to WikiLeaks to prevent the election of a candidate with a history of supporting unilateral military action.

Teachers striking and students protesting schools closures.

Harassing individuals associated with a socia movement you disagree with.

\section{Conclusions and Next Steps}

- Online engagement activities may violate social, democratic norms

- We presented a framework to classify an expanded range of online engagement activities

- This matrix decouples the sociality and effectiveness of various actions

- We plan to test the matrix by collecting and analyzing data about citizen attitudes related to a range of online activities

\section{Further Reading}

- Ehrlich, T. (2000). Civic responsibility and higher education. Greenwood Publishing Group.

Freelon, D. (2015). Discourse architecture, ideology, and democratic norms in online political discussion. New Media \& Society, 17(5), 722-791.

Hou, Y., \& Lampe, C. (2015, April). Social media effectiveness for public engagement: Example of small nonprofits. In Proceedings of the SIGCHI Conference on Human Factors in Computing Systems (pp. 3107-3116). ACM.

Voida, A., Harmon, E., \& Al-Ani, B. (2011, May). Homebrew databases: Complexities of everyday information management in nonprofit organizations. In Proceedings of the SIGCHI Conference on Human Factors in Computing Systems (pp. 915924.) ACM.

Wilson, D. S., \& O'Gorman, R. (2003). Emotions and actions associated with norm-breaking events. Human nature, 14(3), 277-304.

World Health Organization. (2014). Measuring Quality of Life Retrieved from http://www.who.int/healthinfo/survey/whoqolqualityoflife/en/ 